\title{
Effective treatment of a steroid-induced femoral neck fracture nonunion with a once-weekly administration of teriparatide in a rheumatoid patient: a case report
}

\author{
Yuichi Mitani
}

Received: 10 February 2013 / Accepted: 18 February 2013 / Published online: 29 March 2013

(C) The Author(s) 2013. This article is published with open access at Springerlink.com

\begin{abstract}
Introduction Nonunion of femoral neck fractures frequently occurs in elderly patients. In patients with rheumatoid arthritis, reoperation rates after internal fixation of a displaced femoral neck fracture increase by up to $60 \%$. Revision surgery with arthroplasty is often preferred for nonunion of femoral neck fractures because there are few effective options for conservative treatment. Teriparatide (TPTD) is a human parathyroid hormone analog and the only anabolic drug for the treatment of severe osteoporosis.

Discussion There are two types of treatment regimens using TPTD: a once-daily administration of recombinant type TPTD and a once-weekly administration of a chemically synthesized type. Although there have been some reports showing that the once-daily recombinant type TPTD was effective for nonunion treatment, the effect of a once-weekly administration of the chemically synthesized type of TPTD is unknown. This report shows the efficacy of the chemically synthesized TPTD for the treatment of femoral neck fracture nonunion in a patient with risk factors that include rheumatoid arthritis and steroid intake.
\end{abstract}

Keywords Teriparatide $\cdot$ Nonunion $\cdot$ Femoral neck fracture $\cdot$ Rheumatoid arthritis $\cdot$ Steroids $\cdot$ Osteoporosis

\section{Introduction}

Few options exist for the conservative treatment of delayed union and nonunion fractures, including low-intensity pulsed ultrasound (LIPUS), electrical stimulation, and extracorporeal shock waves [1]. Two bone morphogenetic proteins (BMPs), BMP-2 and BMP-7, are approved as drugs for nonunion fractures, but their use may require additional surgery and, until now, there have been no approved systemic drugs for nonunion [2].

Intermittent administration of teriparatide (TPTD), a human parathyroid hormone analog, is the only currently available anabolic agent to stimulate osteoblast activity [3-6]. TPTD has been shown to increase bone mass, improve bone quality, and reduce the risk of fracture in patients with severe osteoporosis $[5,6]$. The daily or weekly administration of TPTD is dependent on the type of TPTD utilized, with a recombinant type used daily and a chemically synthesized type weekly [7]. Several reports have demonstrated the efficacy of the daily administration of recombinant TPTD in the treatment of nonunion fractures [8-11]; however, it is still unknown whether a weekly administration of chemically synthesized TPTD could offer an effective alternative to the daily regimen. The anabolic effect of the weekly dose of the chemically synthesized TPTD is thus presented in the following case study.

\section{Case presentation}

Department of Orthopedic Surgery, Nagano Hospital,

Nippon Telegraph and Telephone East Co. Ltd,

1-2-43 Miwa, Nagano, Japan 380-0803

Y. Mitani $(\bowtie)$

Kitamoto Orthopedic Clinic, 1-33 Kitamoto,

Kitamoto, Saitama, Japan 364-0006

e-mail: yxmitani@hotmail.com
An 88-year-old female was referred to our hospital in February 2011 after a fall from her bed 3 days earlier. Her past medical history included colon cancer at the age of 67 years and gastric cancer at the age of 85 years. She suffers from rheumatoid arthritis (RA), with a drug history of $50 \mathrm{mg}$ 
Fig. 1 Radiograph (a) and CT imaging (b) show a Garden type II displaced femoral neck fracture at the time of arrival, which was fixed with a Hansson hook-pin system $(\mathbf{c})$
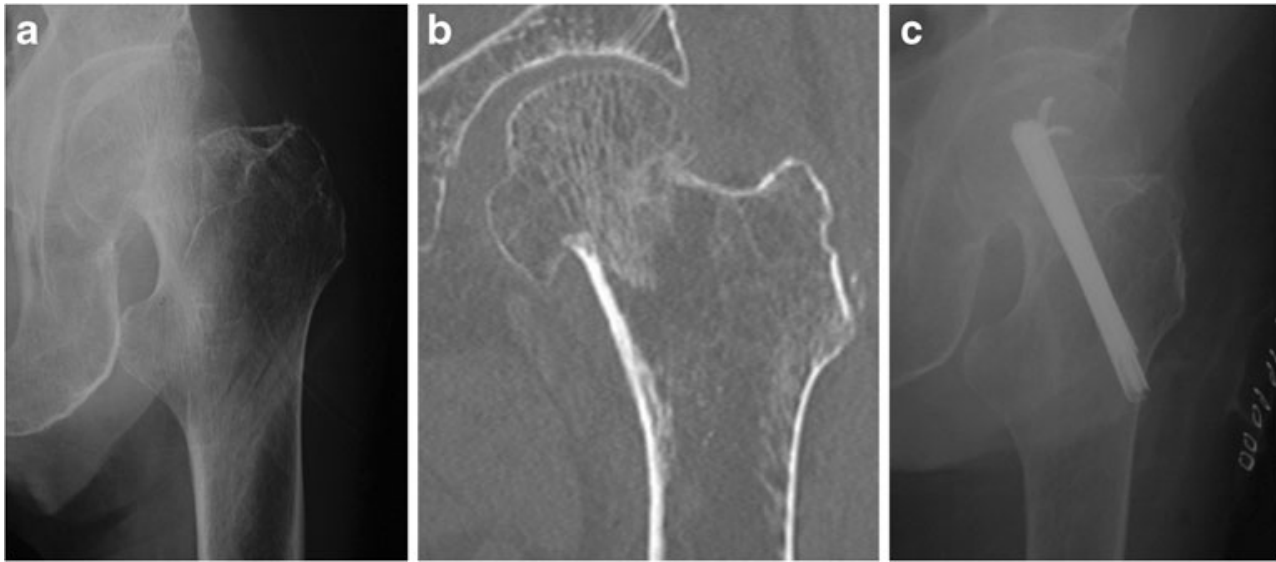

bucillamine and $5 \mathrm{mg}$ prednisolone per day for more than 10 years. Two months prior to her fall, her prednisolone dosage had been reduced to $2.5 \mathrm{mg}$ per day. Clinical and radiological examination revealed a Garden type II displaced femoral neck fracture. The patient underwent surgery with a Hansson hook-pin system within $3 \mathrm{~h}$ after her arrival (Fig. 1).

At 3 months post-operatively, CT imaging suggested the presence of delayed union in the femoral neck, which was treated with LIPUS (Fig. 2a). At 11 months, the patient still complained of mild groin pain on ambulation. A diagnosis of nonunion was given but LIPUS therapy was discontinued because the patient rejected the therapy (Fig. 2b). Bone mineral density (BMD) tests of the right hip revealed severe osteoporosis measuring $38 \%$ of the young adult mean, with a BMD score of $0.303 \mathrm{~g} / \mathrm{cm}^{2}$ and a $T$ score of -4.4 .

The patient accepted treatment with a once-weekly injection of $56.5 \mu \mathrm{g}$ chemically synthesized TPTD. At 18 months post-operatively, CT imaging after 20 consecutive weekly administrations of TPTD revealed signs of healing and the patient reported a gradual decrease in groin pain on ambulation (Fig. 2c). Complete union of the fracture was obtained at 23 months (Fig. 2d). Serum examination after 36 weekly injections of TPTD was as follows: C-reactive protein, $0.2 \mathrm{mg} / \mathrm{dl}$; rheumatoid factor, $170 \mathrm{U} / \mathrm{ml}$; alkaline phosphatase,
$208 \mathrm{U} / 1$; albumin, $4.0 \mathrm{~g} / \mathrm{dl}$; calcium, $8.8 \mathrm{mg} / \mathrm{dl}$. The patient reported no side effects during the entire period of TPTD treatment.

\section{Discussion}

The risk of nonunion after internal fixation in elderly patients with femoral neck fracture is approximately 20 to $35 \%$ [12]. In RA patients, up to $60 \%$ of patients treated with internal fixation of displaced femoral neck fractures require revision surgery [13]. This is likely because of the reduced mineralization rate in the bones of RA patients, which in turn contributes to the poor mechanical stability and resultant implant failure and nonunion of the femoral neck [13]. Aside from RA itself, underlying anemia, poor nutrition, and prolonged systemic corticosteroid use are also significant risk factors that prevent fracture healing in the patient [14]. Taking into account the increased incidence of delayed and nonunion femoral neck fractures in RA patients, arthroplasty might have been a better surgical choice for this patient. However, because the patient was reluctant to undergo revision surgery and she suffered from severe osteoporosis, a regime consisting of a once-weekly dose of TPTD was chosen.
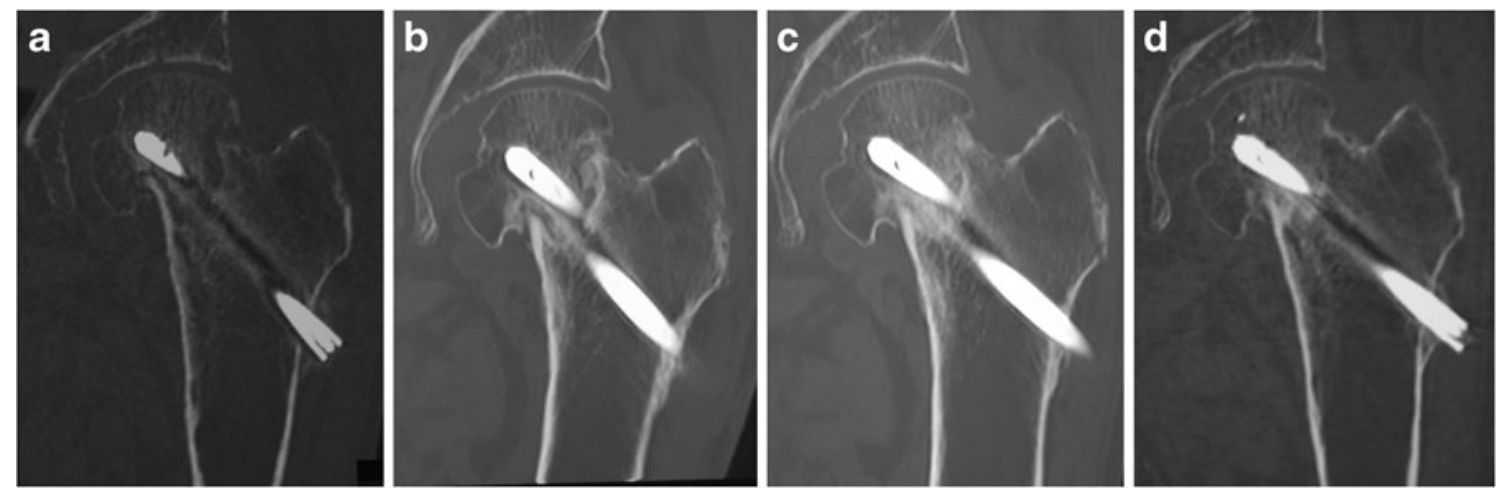

Fig. 2 CT imaging at 3 months (a), 11 months (b), 18 months (c), and 23 months (d) CT imaging at 23 months shows that complete union was obtained after 36 consecutive weekly administrations of teriparatide 
TPTD is the only anabolic drug currently available for osteoporosis patients with an increased risk of fracture [5, 7]. TPTD has a strong anabolic activity on bone through the activation of osteoblasts $[3,4]$. The once-daily administration of recombinant type TPTD has recently been reported to be effective for treatment of nonunion fractures, including humerus, odontoid, sternum, and femoral neck fractures [8-11]. Of particular interest, patients in the report of femoral neck fractures had no complications [11]. Thus, this is the first report to show the efficacy of a onceweekly administration of chemically synthesized TPTD in a nonunion patient with RA and steroid use. Further well-designed studies should be performed to confirm the results of this case report.

\section{Conflicts of interest None.}

Open Access This article is distributed under the terms of the Creative Commons Attribution Noncommercial License which permits any use, distribution, and reproduction in any medium, provided the original author(s) and the source are credited.

\section{References}

1. Walker NA, Denegar CR, Preische J (2007) Low-intensity pulsed ultrasound and pulsed electromagnetic field in the treatment of tibial fractures: a systematic review. J Athl Train 42:530-535

2. Kim M, Choe S (2011) BMPs and their clinical potentials. BMB Rep 44(10):619-634

3. Borggrefe J, Graeff C, Nickelsen TN, Marin F, Gluer CC (2010) Quantitative computed tomographic assessment of the effects of 24 months of teriparatide treatment on 3D femoral neck bone distribution, geometry, and bone strength: results from the EUROFORS study. J Bone Miner Res 25:472-481

4. Miki T, Nakatsuka K, Naka H, Masaki H, Imanishi Y, Ito M, Inaba M, Morii H, Nishizawa Y (2004) Effect and safety of intermittent weekly administration of human parathyroid hormone 1-34 in patients with primary osteoporosis evaluated by histomorphometry and microstructural analysis of iliac trabecular bone before and after 1 year of treatment. J Bone Miner Metab 22:569-576

5. Sibai T, Morgan EF, Einhorn TA (2011) Anabolic agents and bone quality. Clin Orthop Relat Res 469:2215-2224

6. Konstantinos AT, Anastasilakis AD, Polyzos SA, Makras P (2011) Targeting the osteoblast: approved and experimental anabolic agents for the treatment of osteoarthrosis. Hormones 10:174-195

7. Nakamura T, Sugimoto T, Nakano T, Kishimoto H, Ito M, Fukunaga M, Hagino H, Sone T, Yoshikawa H, Nishizawa Y, Fujita T, Shiraki M (2012) Randomized Teriparatide [human parathyroid hormone (PTH) 1-34] Once-Weekly Efficacy Research (TOWER) trial for examining the reduction in new vertebral fractures in subjects with primary osteoporosis and high fracture risk. J Clin Endocrinol Metab 97:3097-3106

8. Oteo-Alvaro A, Moreno E (2010) Atrophic humeral shaft nonunion treated with teriparatide (rh PTH 1-34): a case report. J Should Elb Surg 19:e22-e28. doi:10.1016/j.jse.2010.05.005

9. Rubery PT, Bukata SV (2010) Teriparatide may accelerate healing in delayed unions of type III odontoid fractures: a report of 3 cases. J Spinal Disord Tech 23:151-155

10. Chintamaneni S, Finzel K, Gruber BL (2010) Successful treatment of sternal fracture nonunion with teriparatide. Osteoporos Int 21:1059-1063

11. Lee YK, Ha YC, Koo KH (2012) Teriparatide, a nonsurgical solution for femoral nonunion? A report of three cases. Osteoporos Int 23:2897-2900

12. Parker MJ (2000) The management of intracapsular fractures of the proximal femur. J Bone Joint Surg Br 82:937-941

13. Bogoch E, Ouellette O, Hastings D (1991) Failure of internal fixation of displaced femoral neck fractures in rheumatoid patients. J Bone Joint Surg Br 73:7-10

14. Gaston MS, Simpson AH (2007) Inhibition of fracture healing. J Bone Joint Surg Br 89:1553-1560 